\title{
SELEÇÃO [2015-2017]
}

Vão

O Vão é uma oficina que se destina à realização de projetos de arte individuais e coletivos. Desde 2015, vem realizando ações e gravuras. O grupo e formado, atualmente, por Hortência Abreu,

As imagens que compõem a sessão Poéticas foram feitas entre junho de 2015 e maio de 2017, na cidade de Belo Horizonte. Também participaram dessas añ Também participaram dessas açoes Clara Albinatti, Laura Berbert, Luisa Horta e Melissa Rocha. As imagens foram realizadas pelas pessoas citadas e a partir de apropriaçóes, como os cartazes do artista argentino Juan Carlos Romero, a quem prestamos homenagem. 


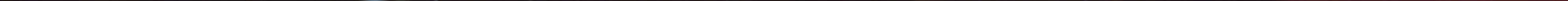


$b^{2}$

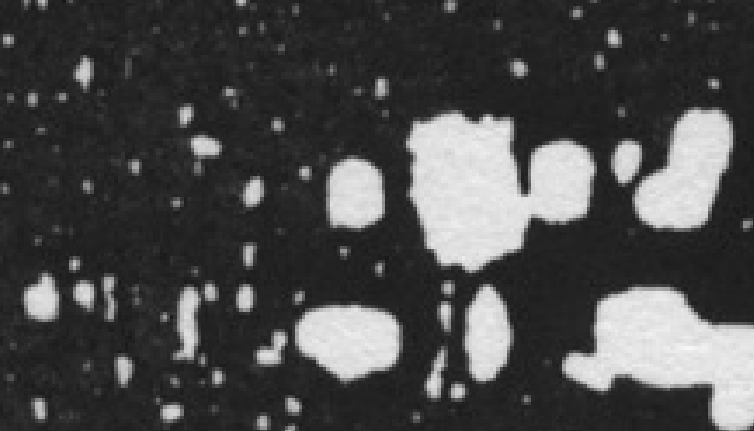

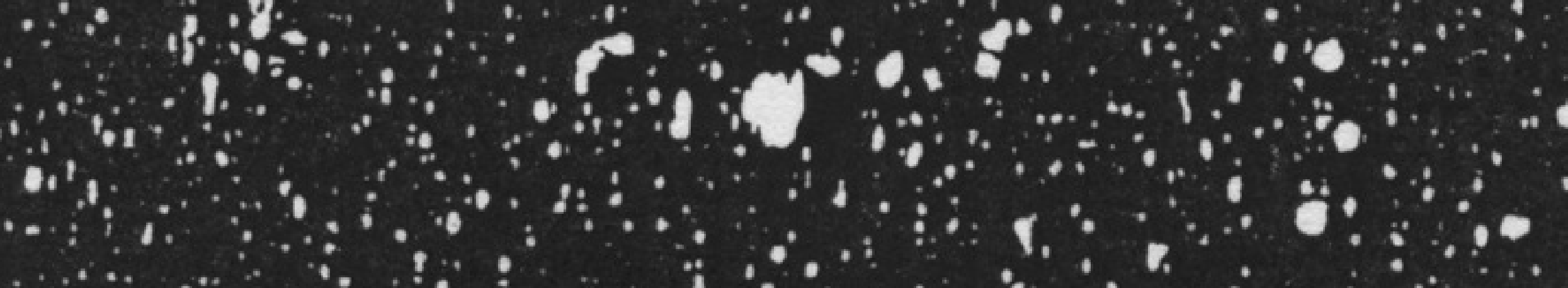

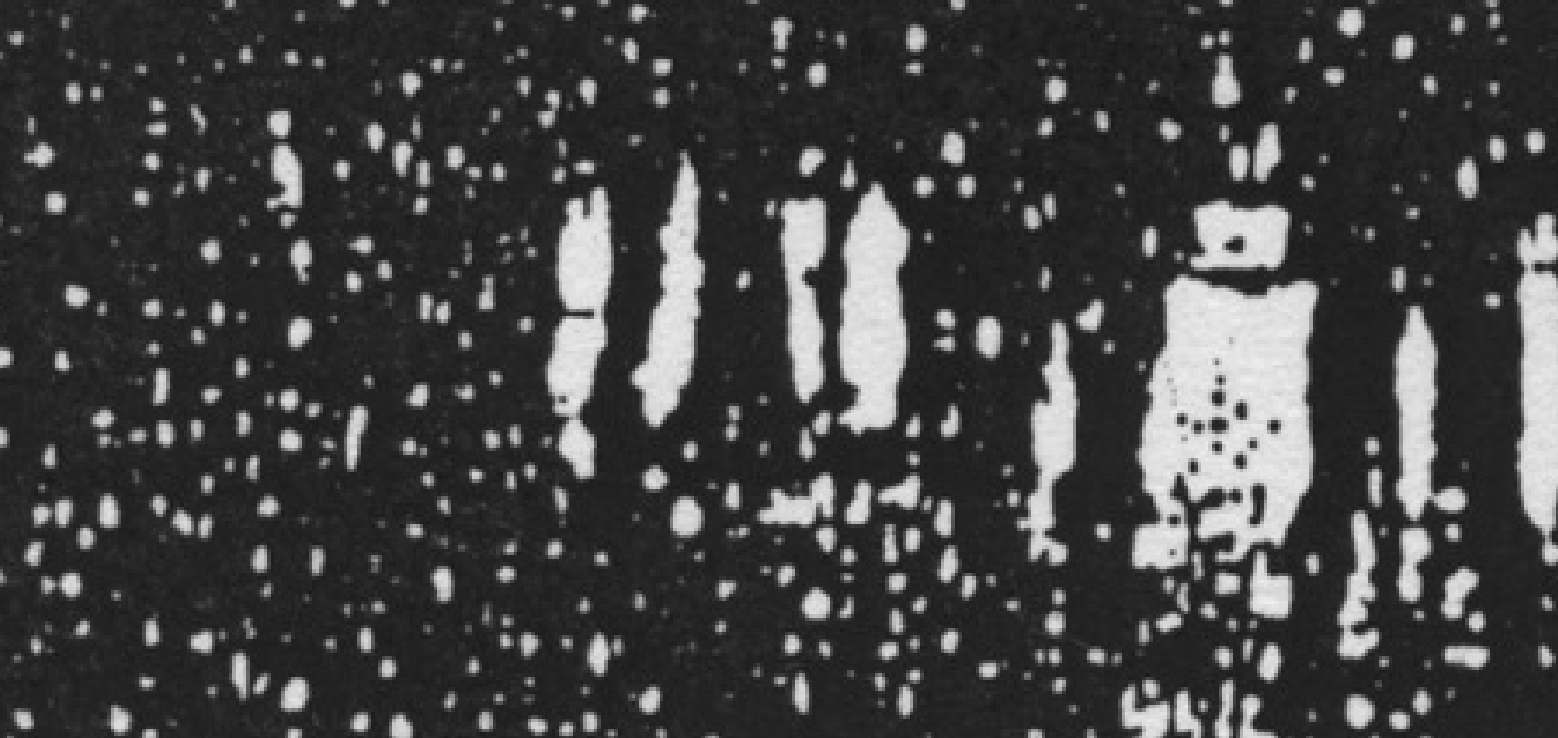

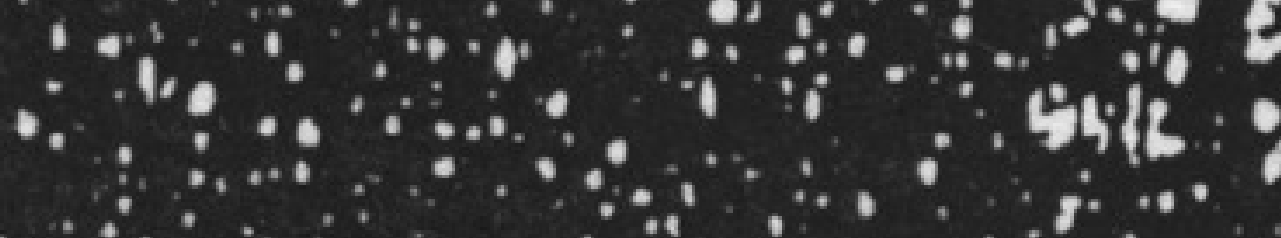
a (1). $\therefore$ $\int_{100}$

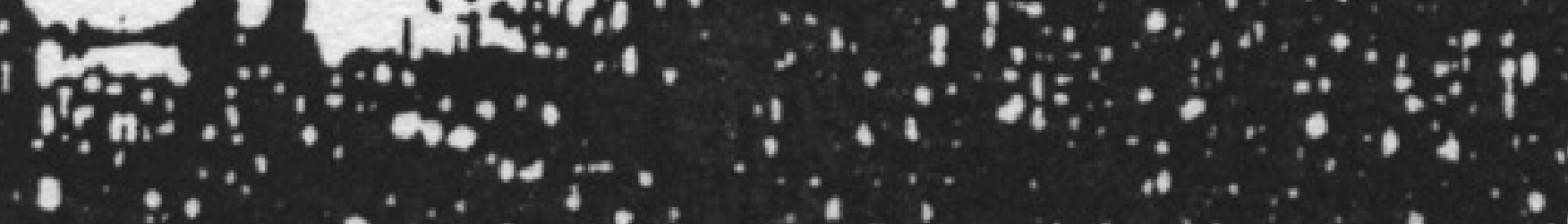

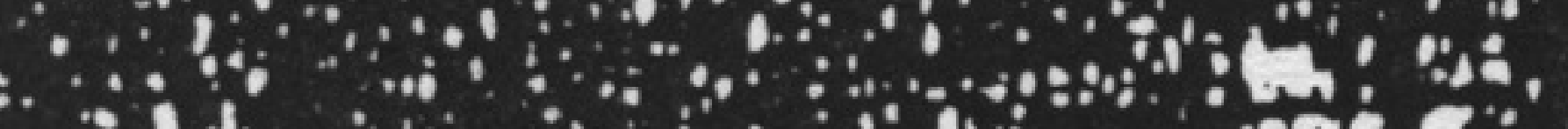

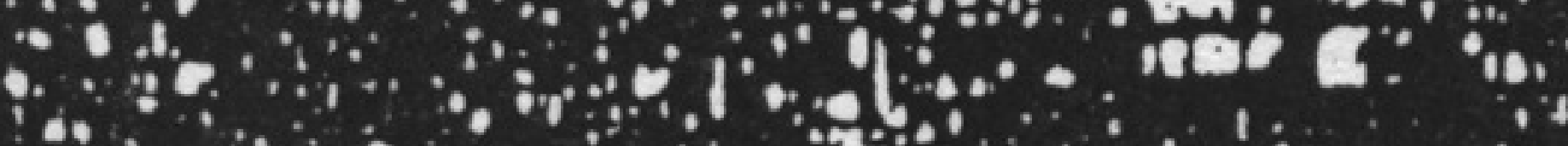
$\because 01000$ $\therefore-1$ to

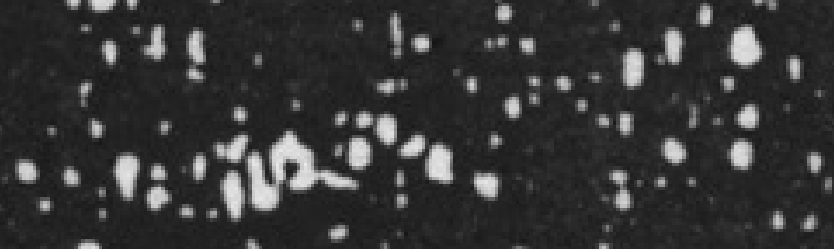



$\therefore+4$

f

$\because 4$

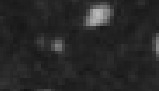

$\because$

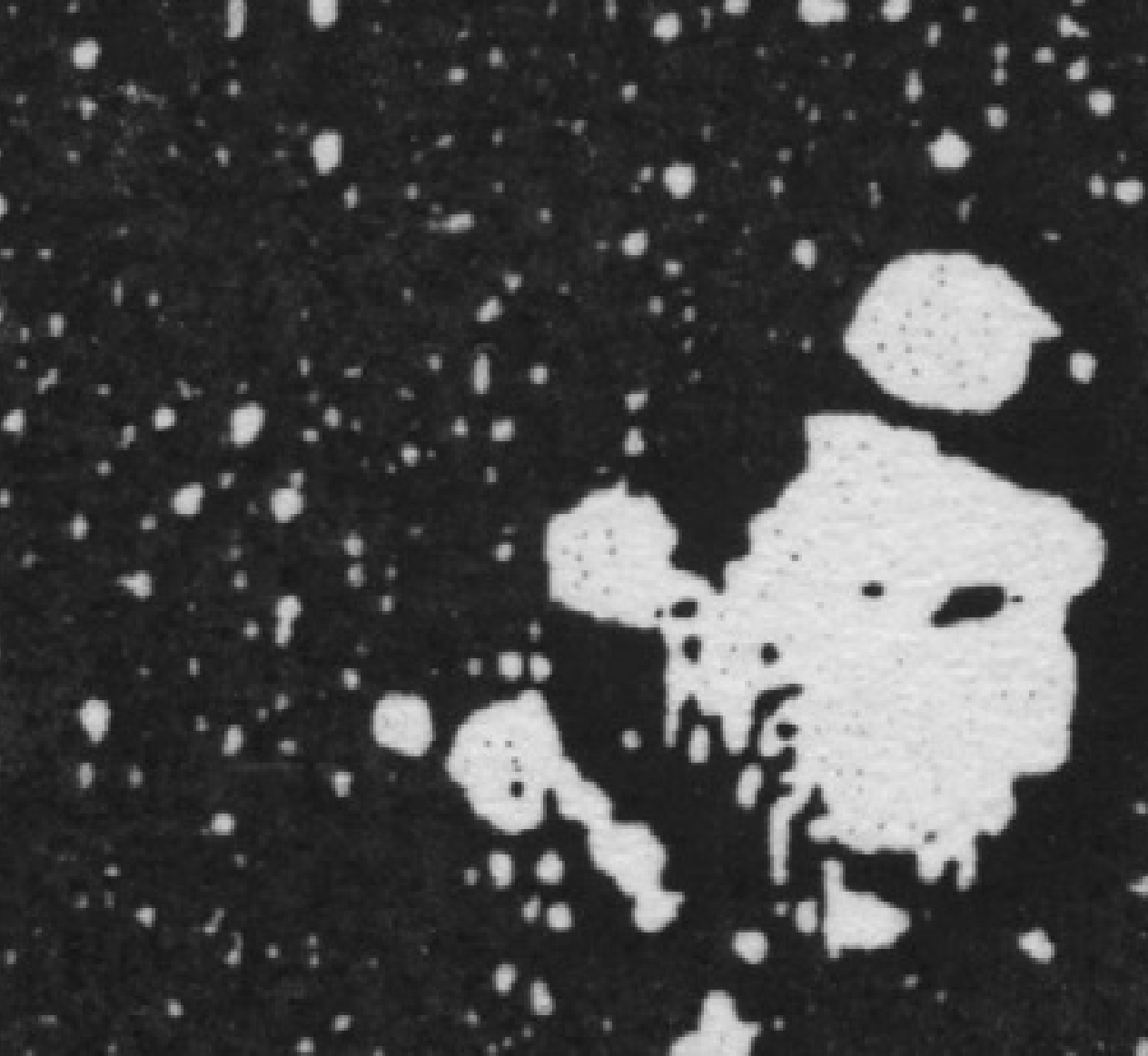

$\therefore$

cold :

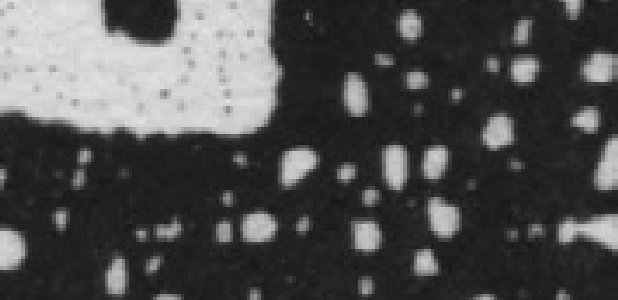

$\because \because \therefore \cdots$

$\therefore$ $\because \because \because \because \cdots, \cdots$

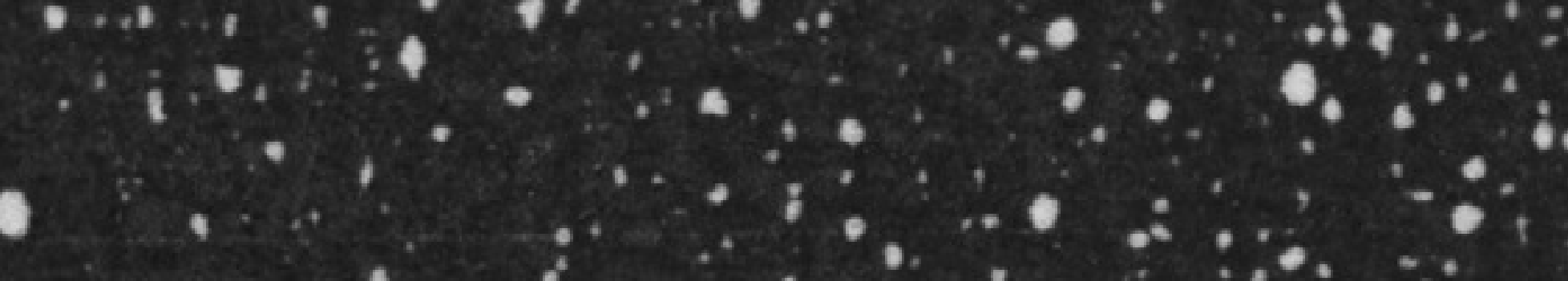

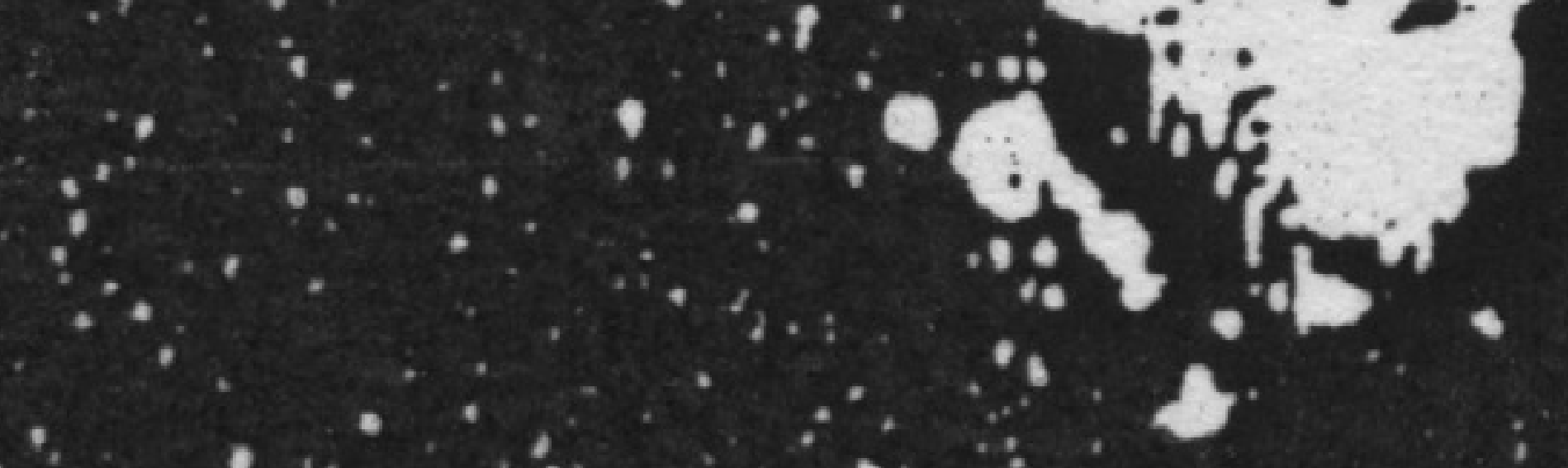

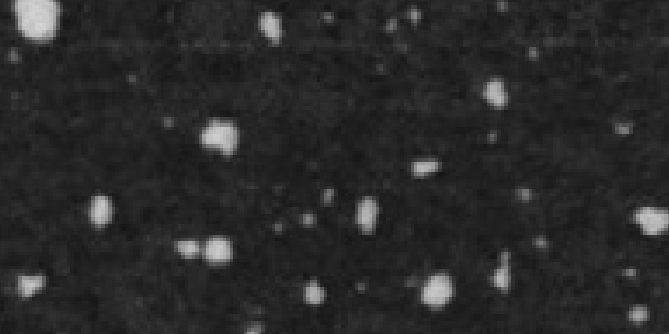
$\because \cdots$ $\cdots$

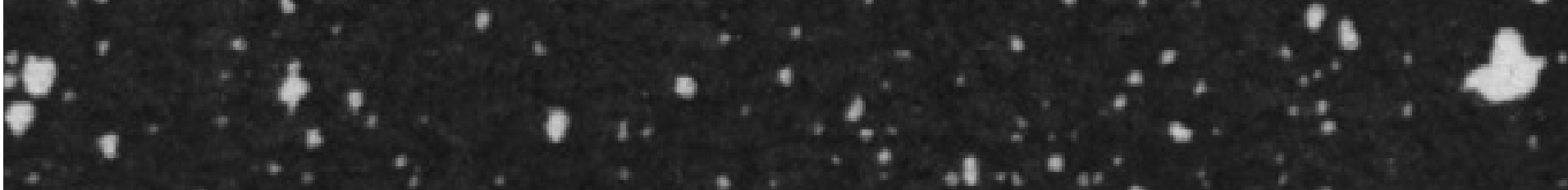

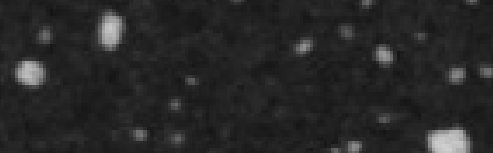

1.

$-$

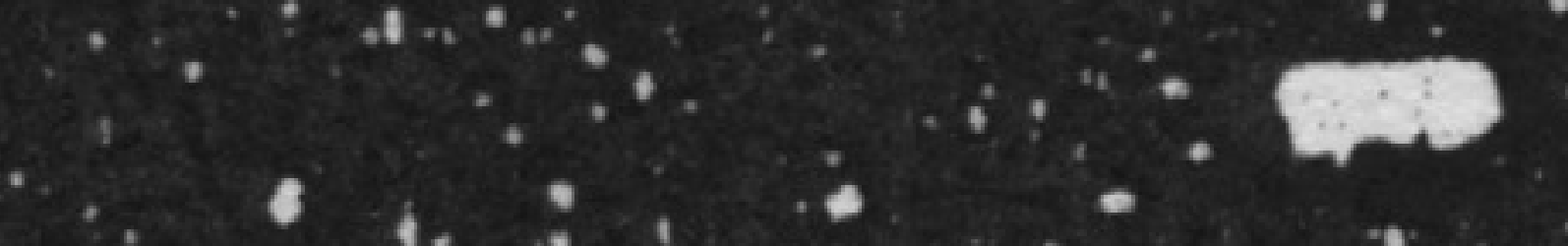

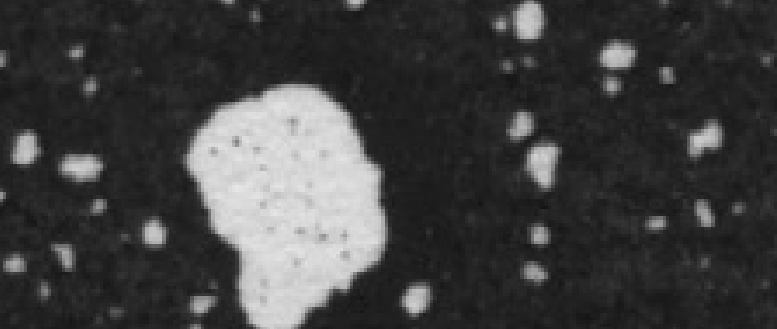

$\checkmark$.

$\dot{v}_{s}:-i=0$ 


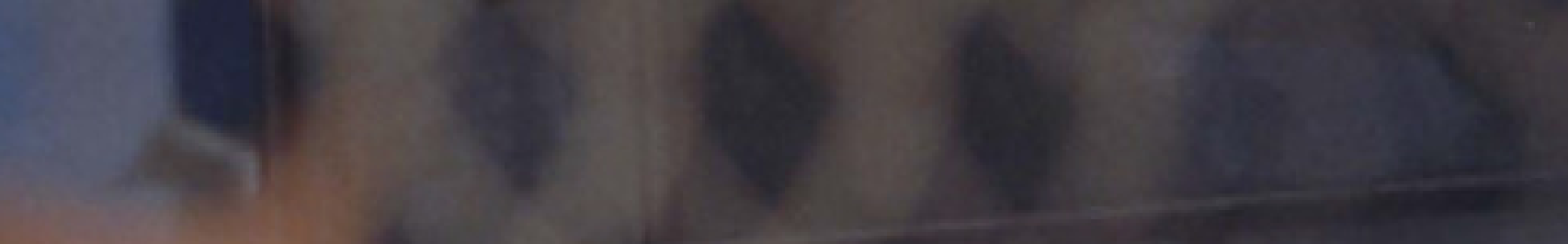

5

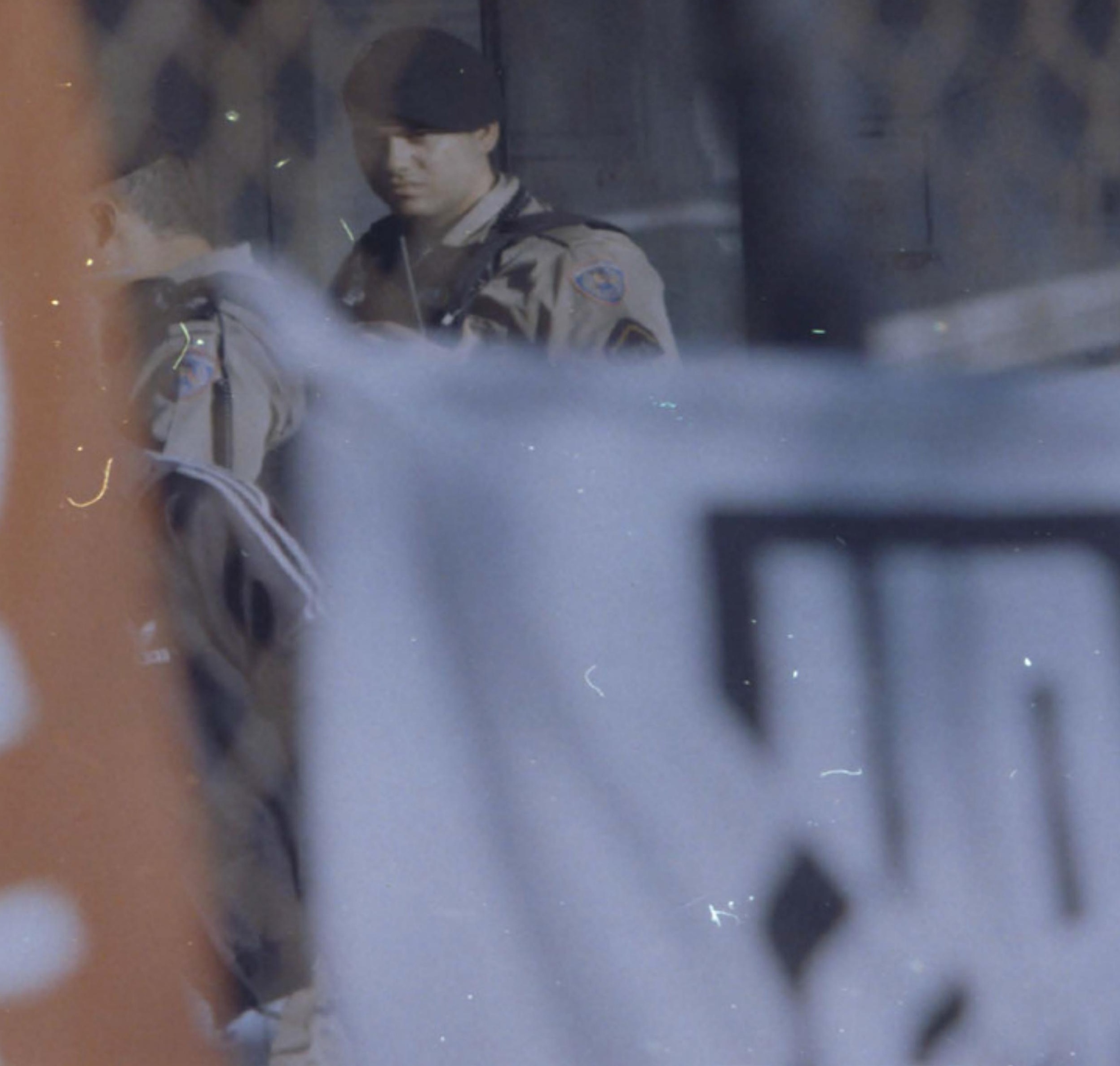




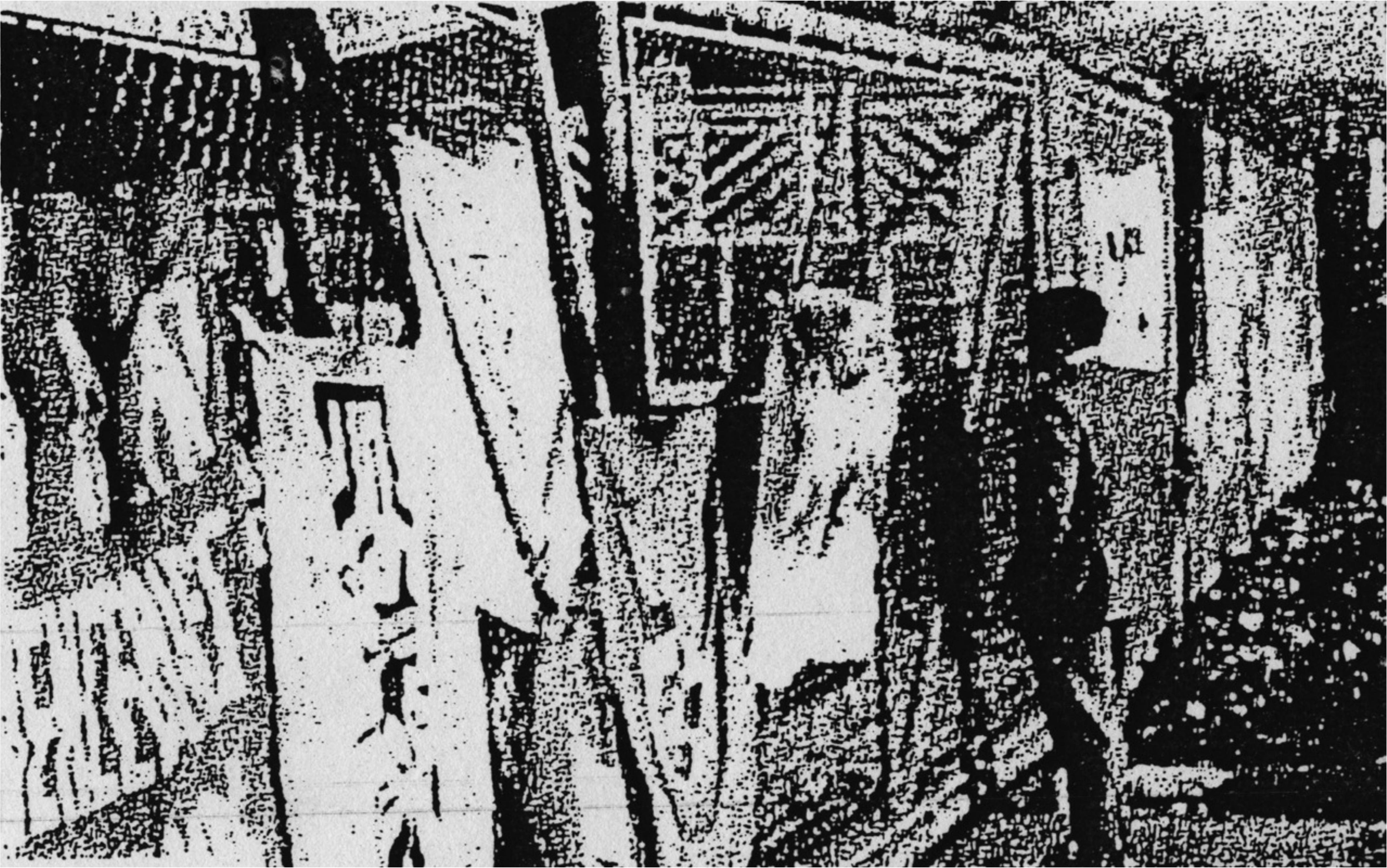




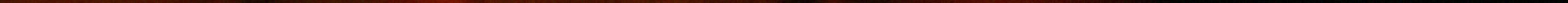




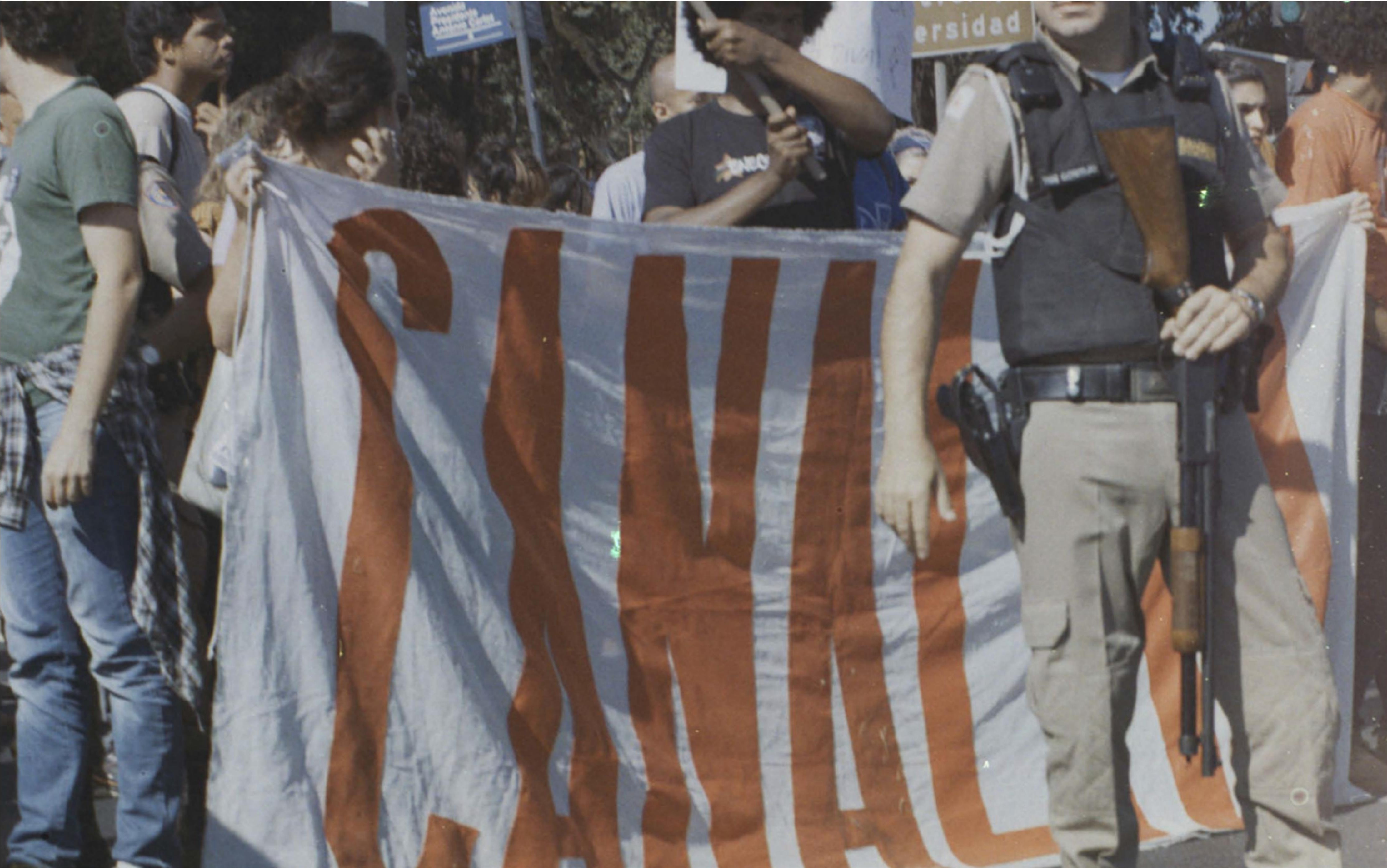




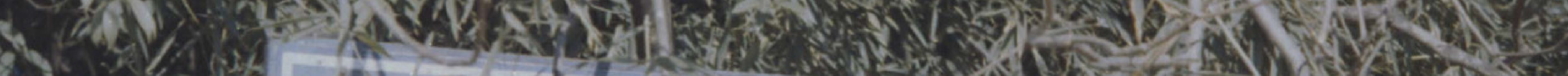
(15) 2010

No6

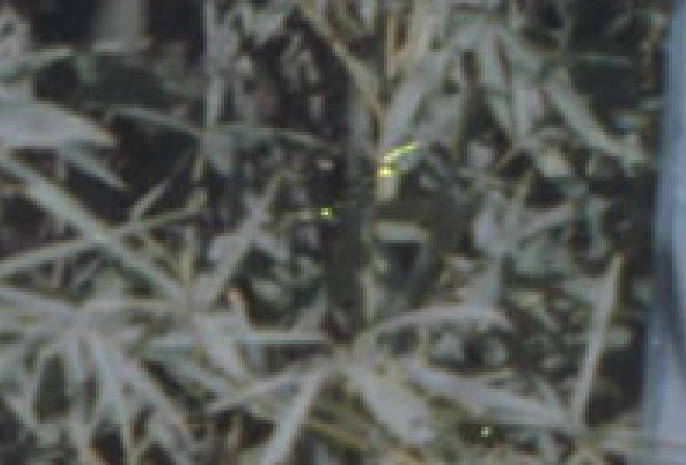

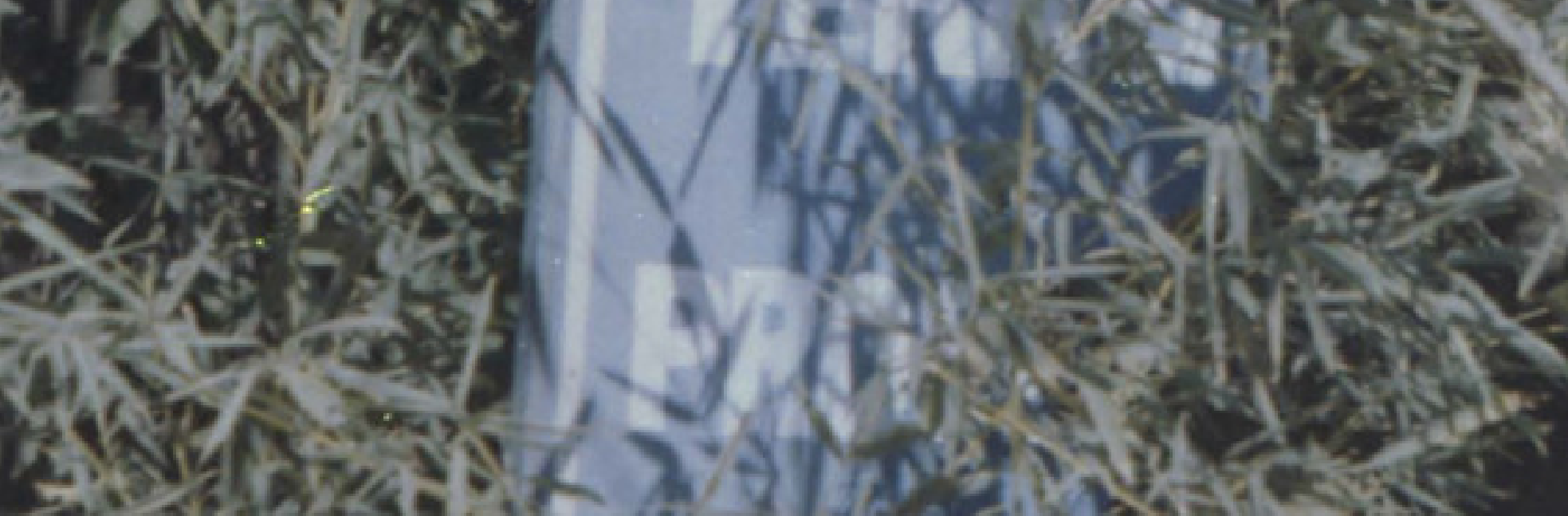
(1) Now

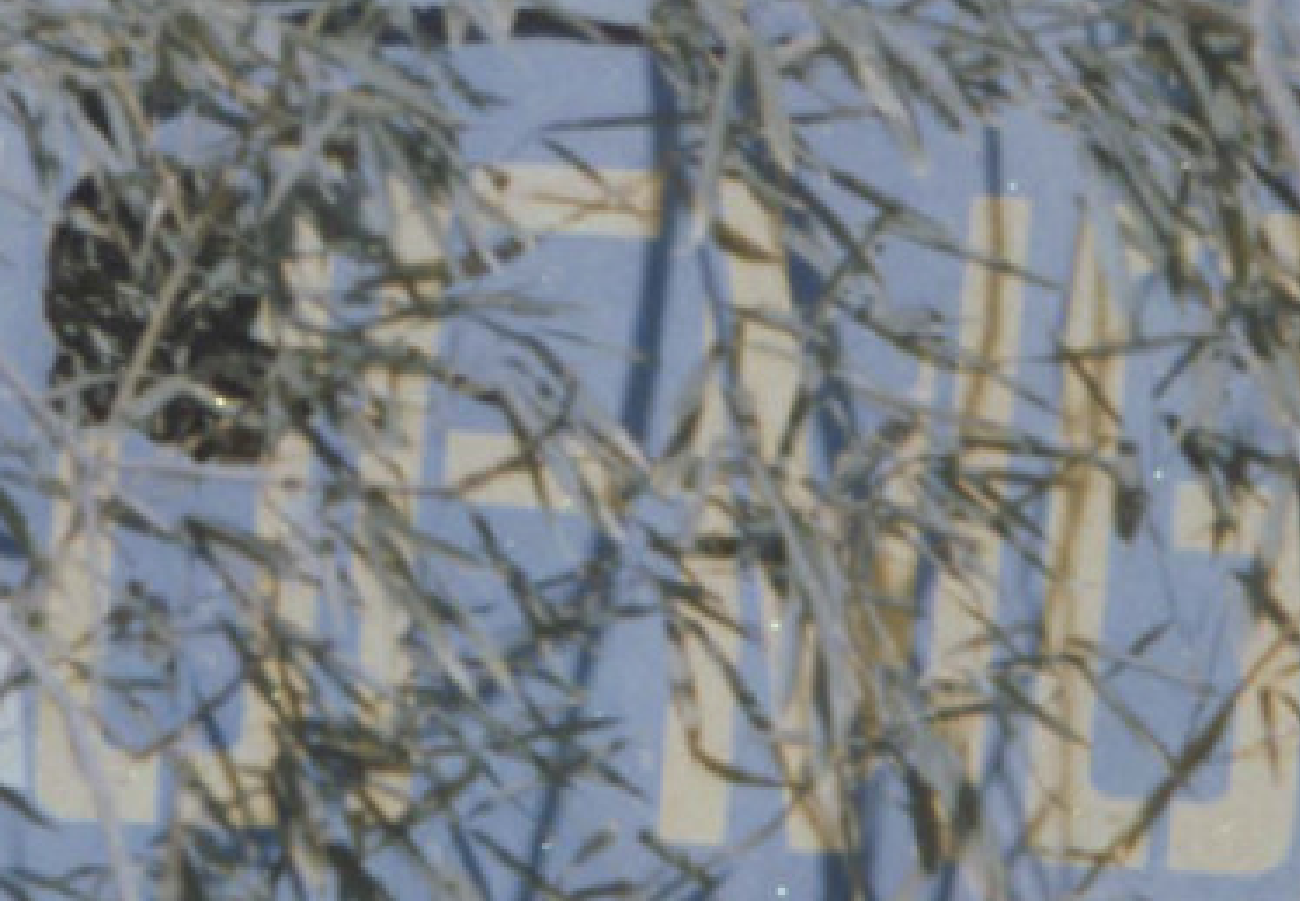

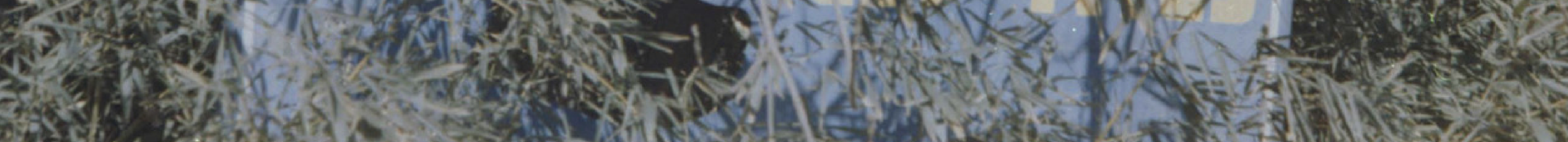

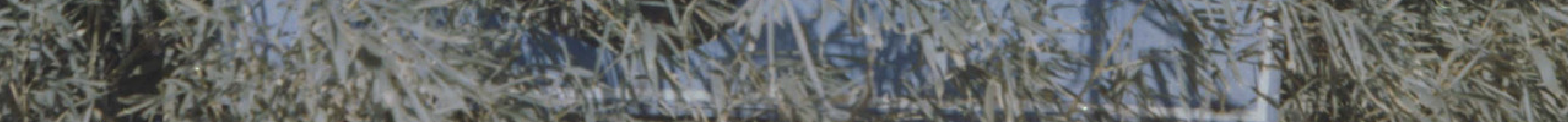
(1)

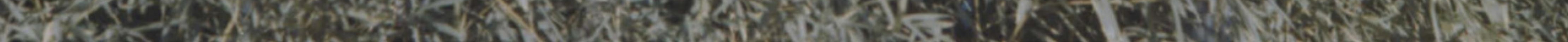




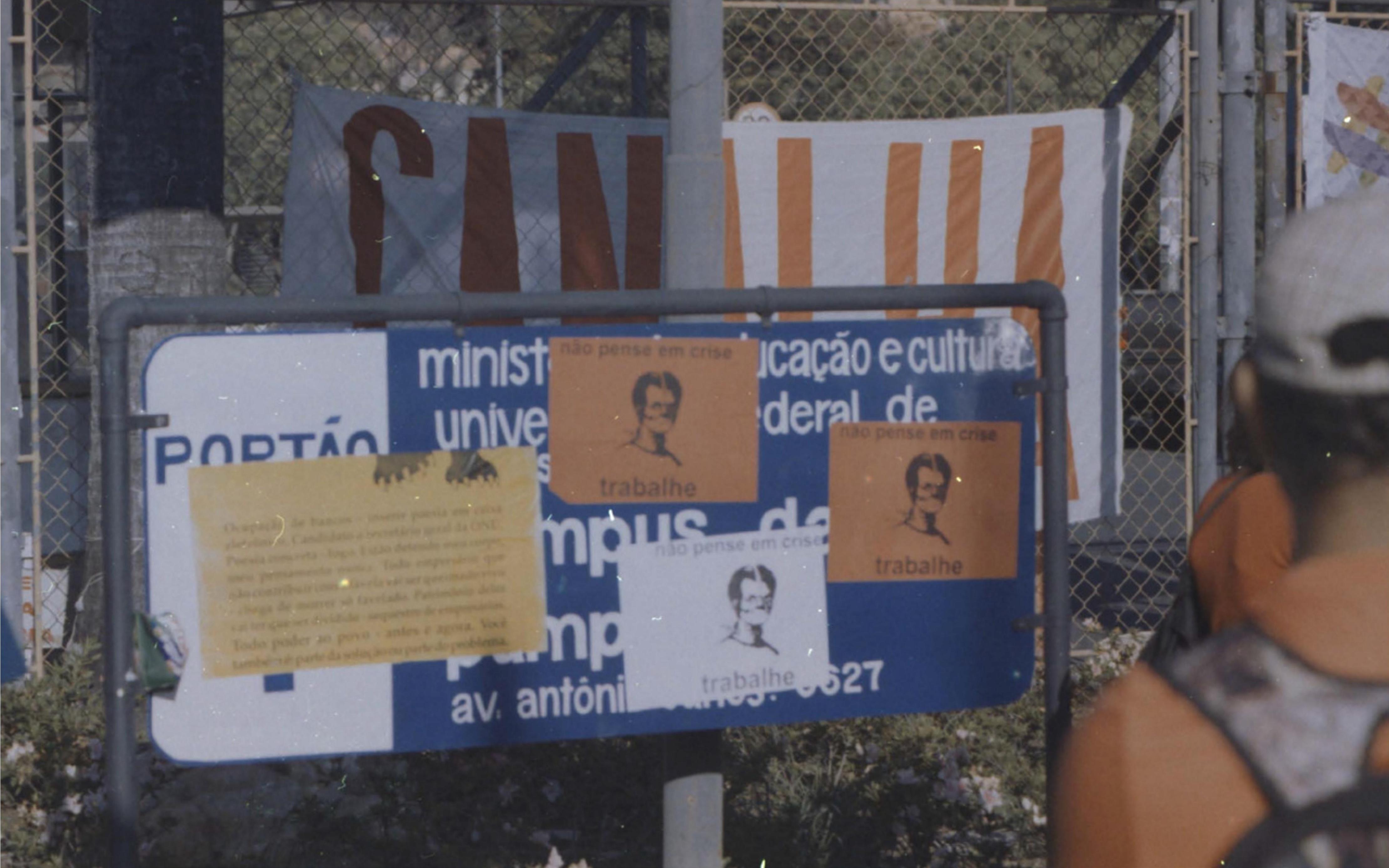



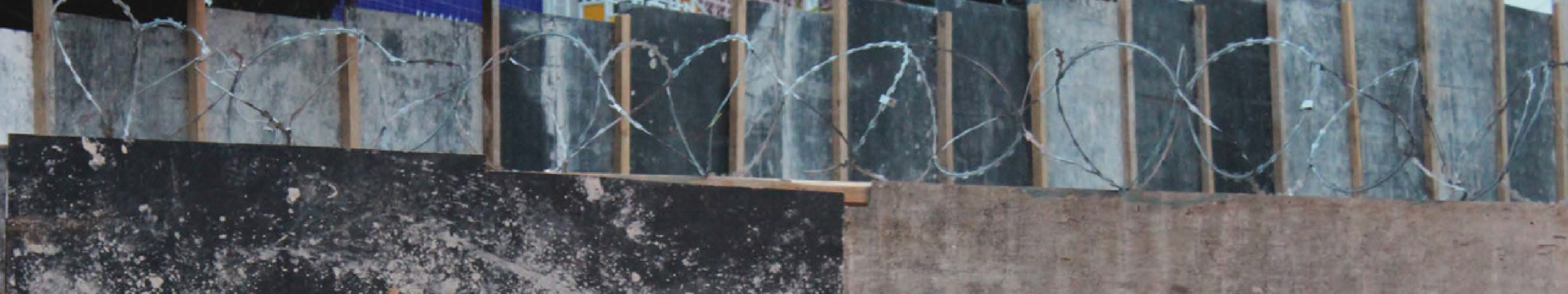

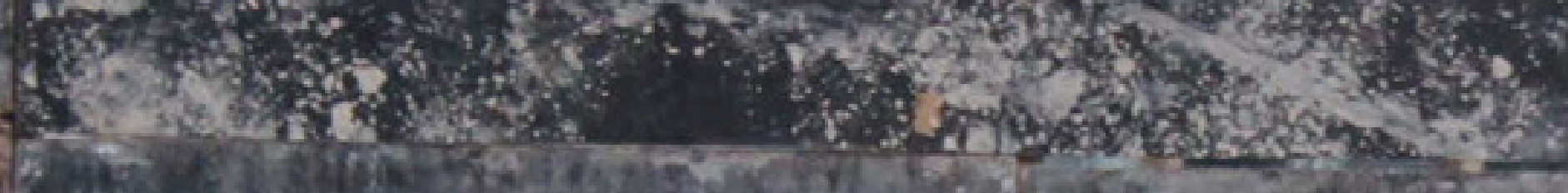
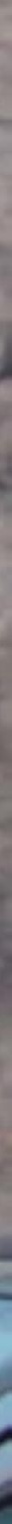

H. 


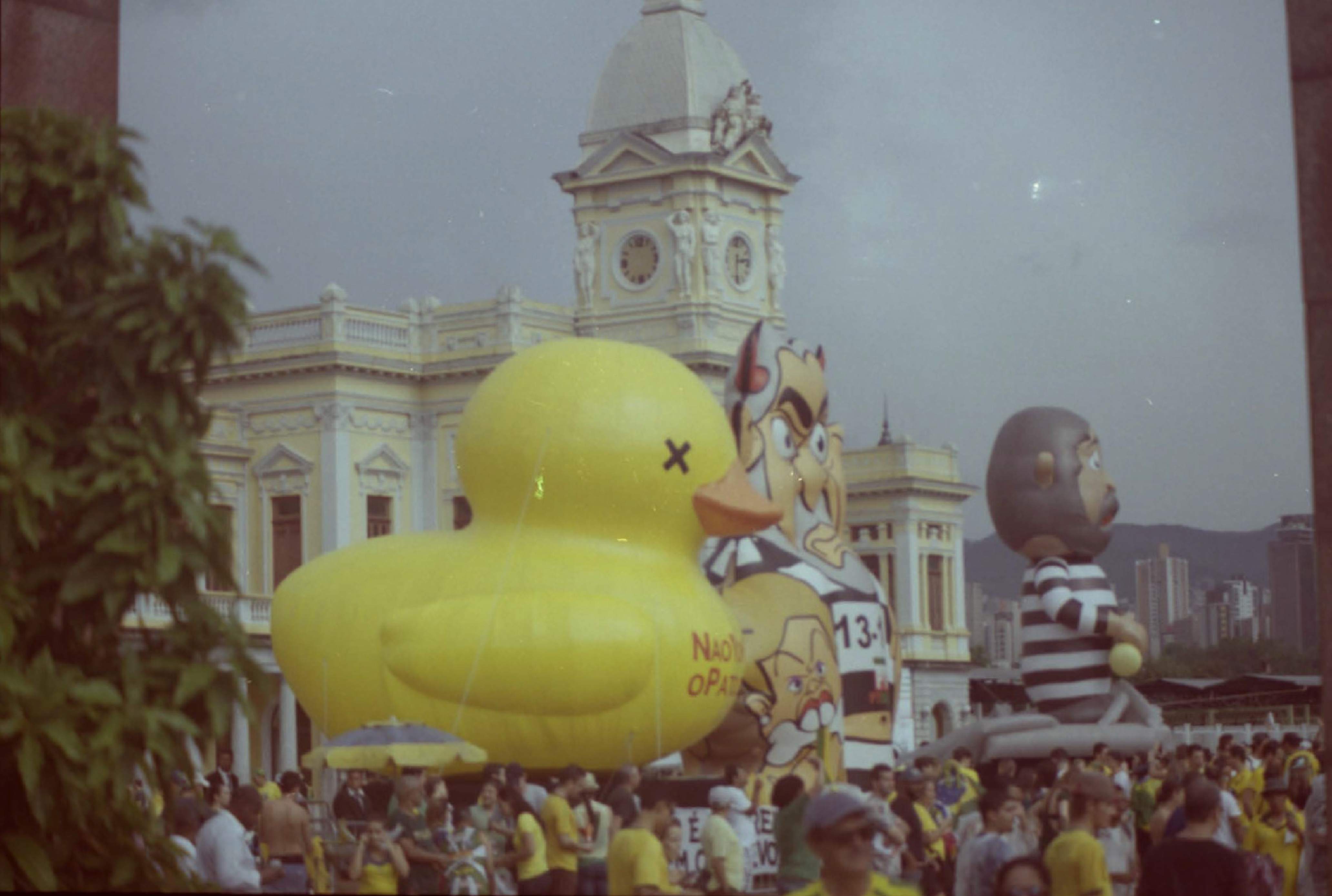




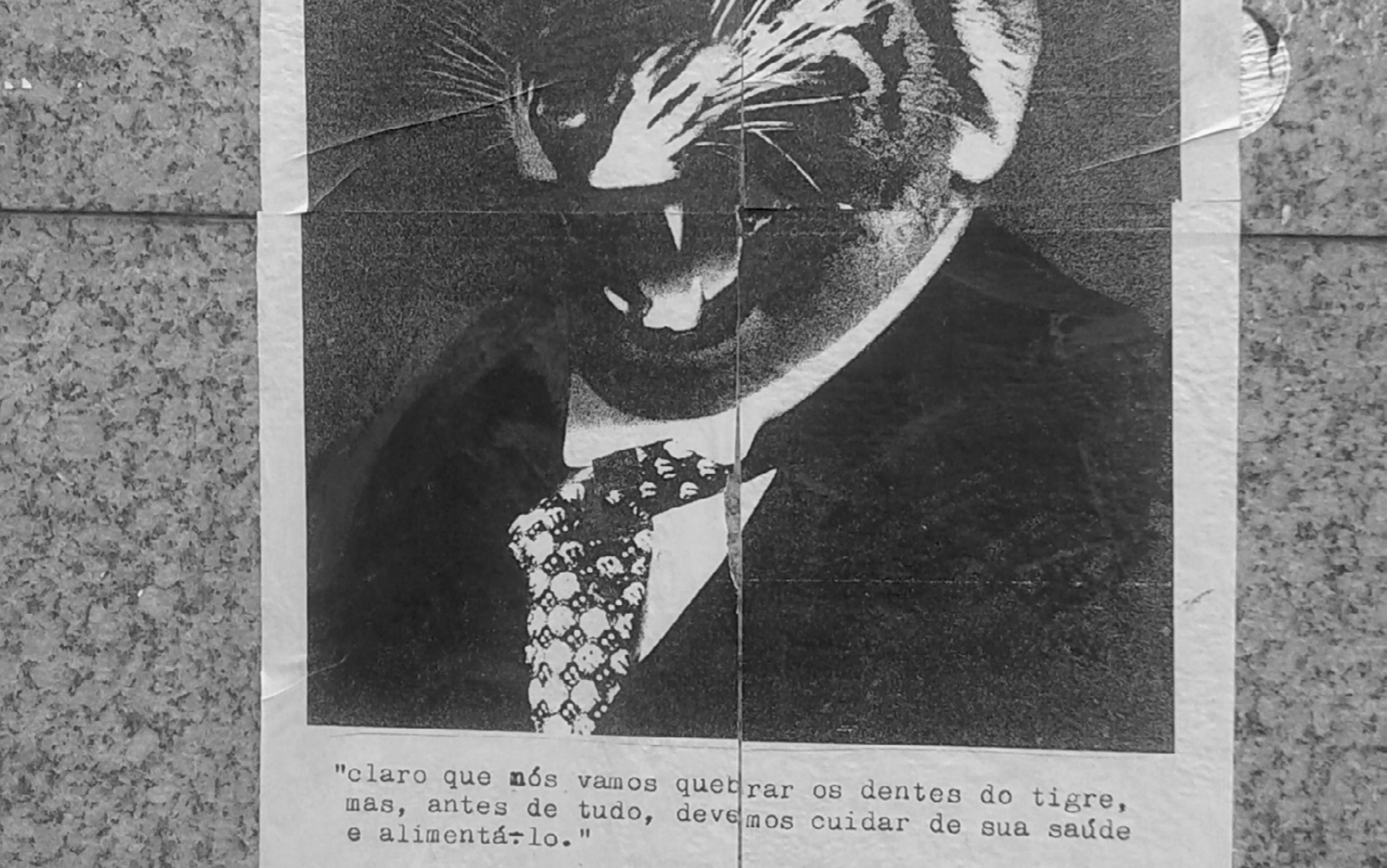




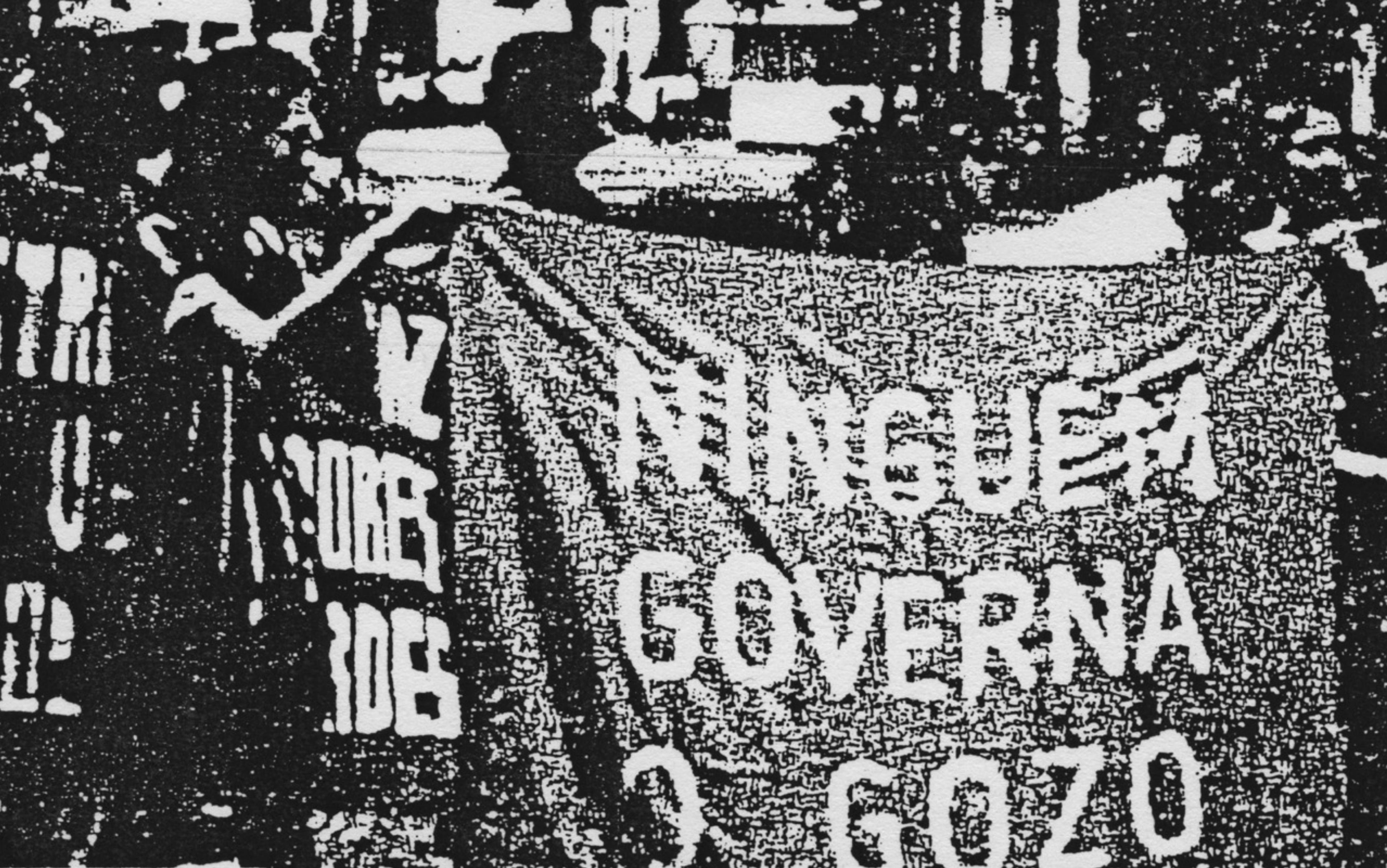




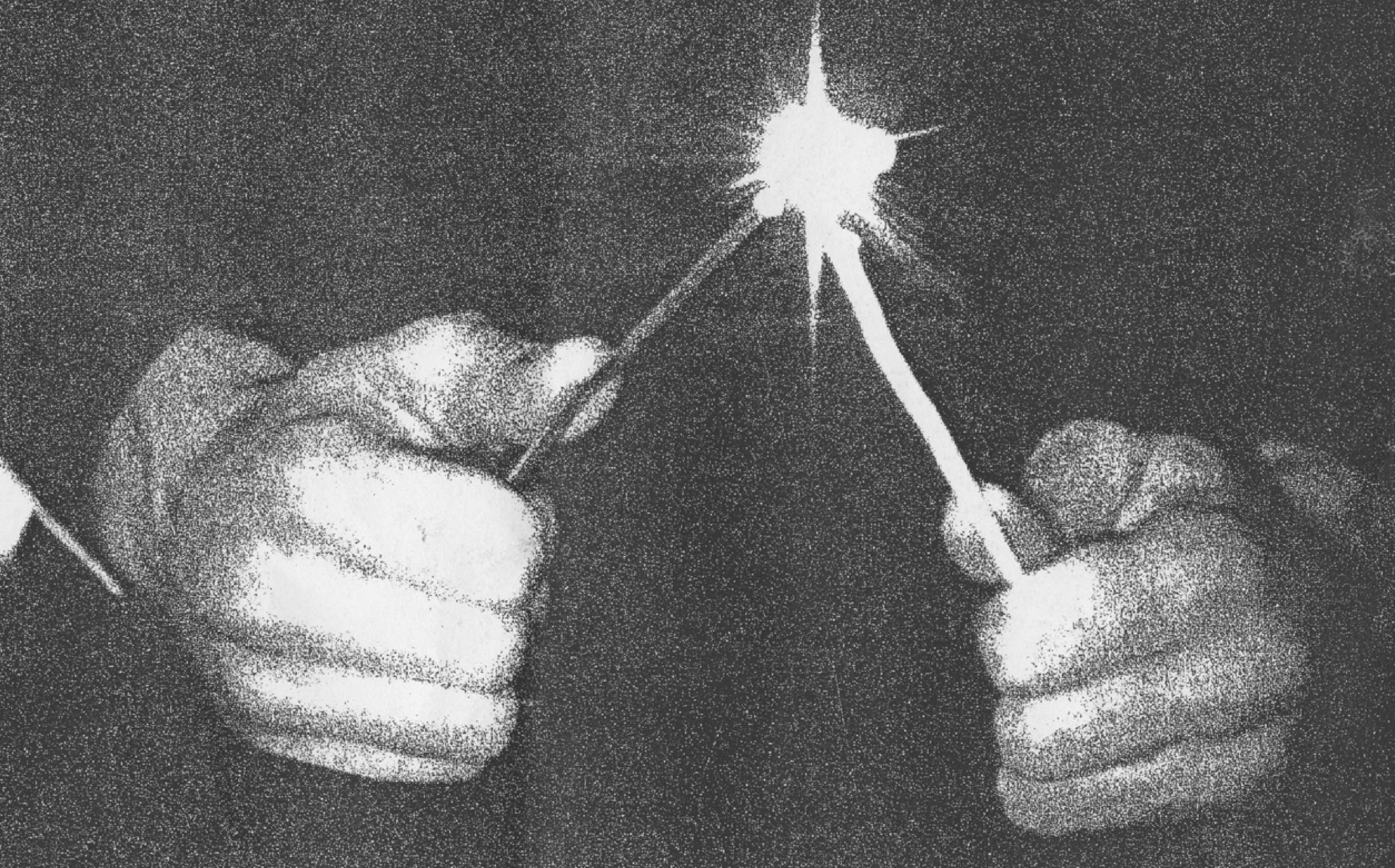




$$
\text { FURIA }
$$




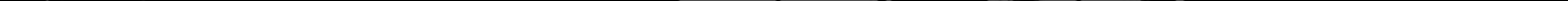




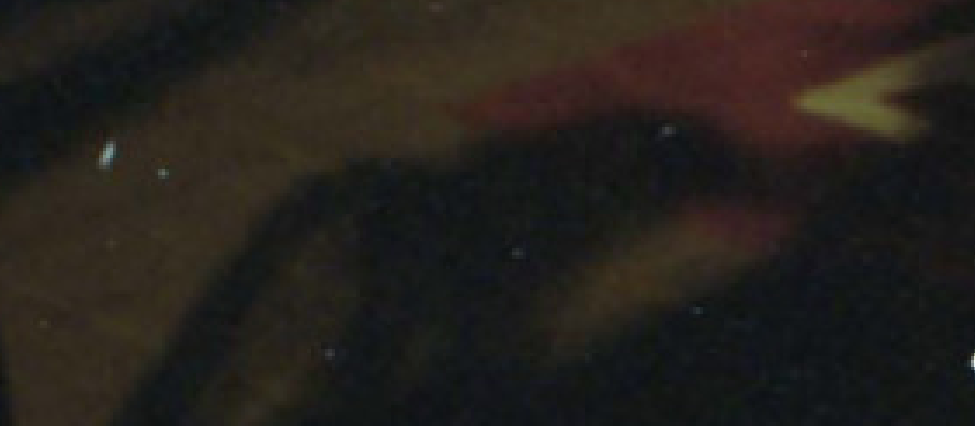

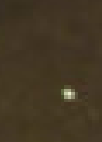

、

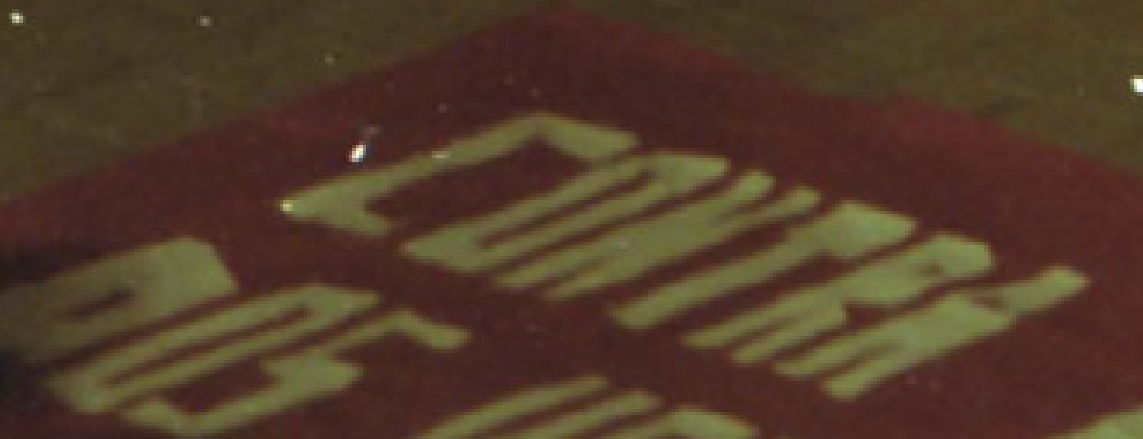

- 20

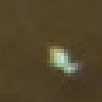




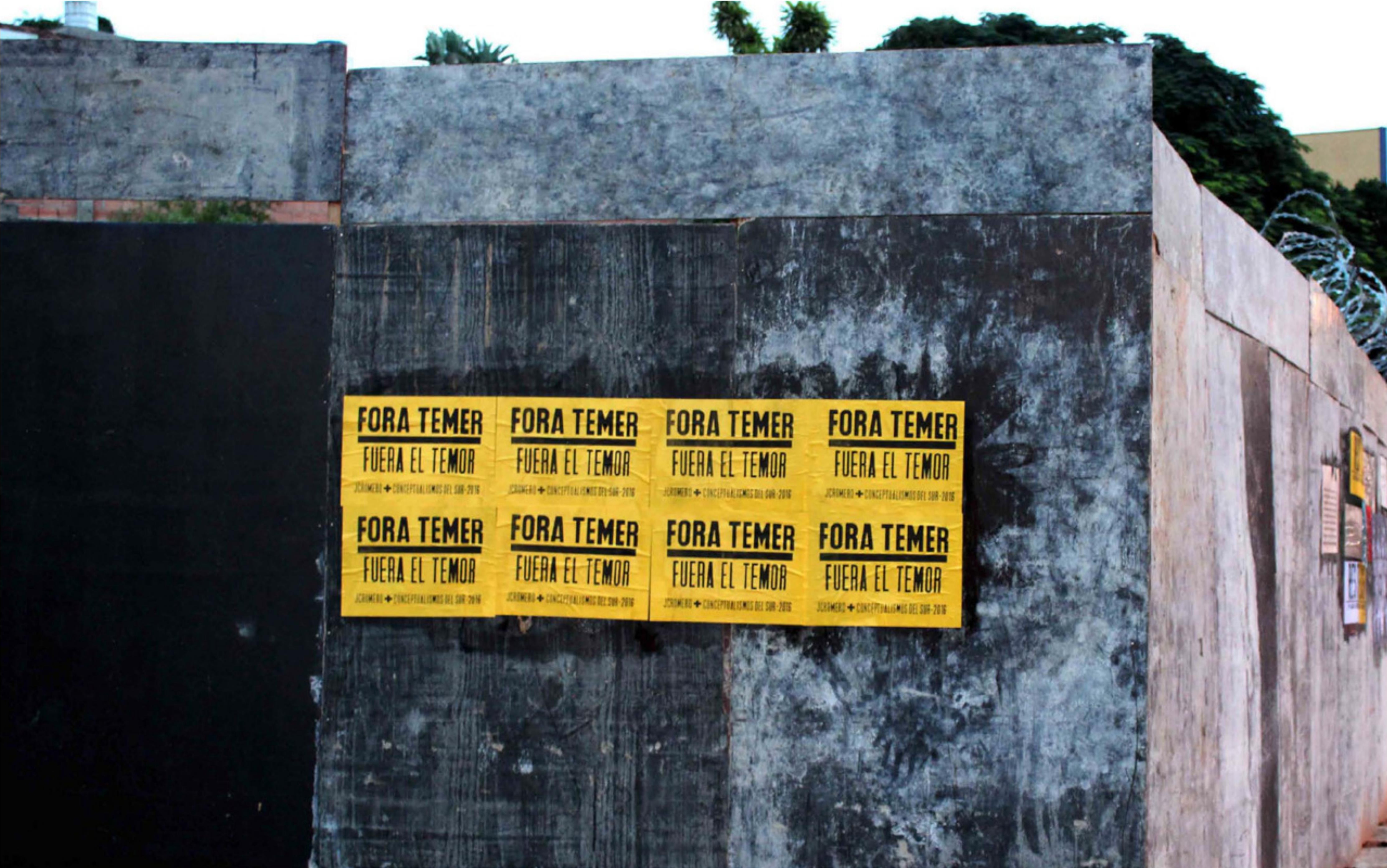





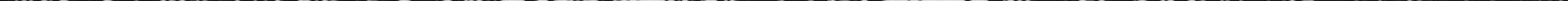

